\title{
Questões acerca do repertório no contexto coral adulto e
}

\section{juvenil}

\author{
Fábio Miguel, Willian Gomes Pedrozo, Emerson Pereira Tineo, Felipe \\ Pillis Panelli, Felipe Rodrigues Ferreira Perez, André dos Santos, Maicon \\ Pereira Jacinto, Regina Célia Corso Marcondes do Amaral \\ Universidade Estadual Paulista | Brasil
}

\begin{abstract}
Resumo: Discorre-se, neste artigo, acerca de questôes relacionadas aos critérios para escolha de repertório, no âmbito coral adulto e no contexto do coro juvenil. A partir de diferentes autores levantamos os parâmetros para seleção de repertório no coral adulto, seguido de um cotejamento entre os critérios sugeridos por cada autor. Em seguida, abordamos os critérios de seleção de repertório coral, com base em pesquisas voltadas para o contexto do coro juvenil seguido de um comparativo dos parâmetros sugeridos pelos autores. Identificamos pontos comuns na seleção de repertório coral adulto e juvenil, mas também, constatamos alguns pontos que são específicos ao coral juvenil.
\end{abstract}

Palavras-chave: coral, coro adulto, coro juvenil, repertório coral, voz cantada.

\begin{abstract}
The discussion in this article revolves around the selection criteria for choral repertoire, specifically in groups formed by adults and young singers. Upon searching different authors, we found different selection parameters for adult choral repertoire, then we proceeded to compare the criteria suggested by each author. In the next step, we analyzed the selection criteria for choral repertoire based on researches involving youth choirs, followed by a comparison between suggested parameters by those researches. In conclusion, there are common practices involving repertoire selection between youth and adult choirs, but, we also discovered selection practices that are specific to youth choirs.
\end{abstract}

Keywords: choral, adult choir, youth choir, choral repertoire, singing voice. 
MIGUEL, Fábio. PEDROZO, Willian Gomes, TINEO, Emerson Pereira, PANELLI, Felipe Pillis, PEREZ, Felipe Rodrigues Ferreira, SANTOS, André dos, JACINTO, Maicon Pereira, AMARAL, Regina Célia Corso Marcondes do. Questões acerca do repertório no contexto coral adulto e juvenil. Revista Vórtex, Curitiba, v.8, n.2, p. 1-27, 2020.

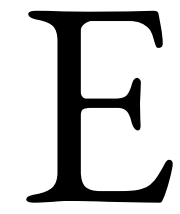

ste artigo é fruto de duas pesquisas realizadas pelo GEPPEVOZIA (Grupo de Estudo, Prática e Pesquisa em Voz do Instituto de Artes da Unesp) que tangenciaram a atividade coral com adolescentes. A primeira, realizada no período de 2015 a 2017, intitulada: Canto coral para adolescentes na escola pública da cidade de São Paulo consistiu na aplicação de oficinas corais, no ensino médio, na escola Miss Browne em São Paulo. Por meio das oficinas buscou-se compreender como desenvolver e ampliar a expressão musical e vocal do adolescente, de modo a contribuir para o seu crescimento humano e artístico-cultural (MIGUEL et. Al., 2017, p. 1).

A segunda pesquisa denominada Voz juvenil no contexto coral: catálogo de obras em língua portuguesa, surgiu de questóes provenientes do estudo mencionado anteriormente, em que questionamos acerca do repertório normalmente considerado adequado para coros de adolescentes. O objetivo desse segundo estudo é elaborar um catálogo com composições e arranjos em língua portuguesa para vozes juvenis, que ficarão disponíveis numa base de dados gratuita online, como sugestão de repertório para regentes, educadores musicais e demais interessados na temática. Tal pesquisa se faz necessária, pois temos observado, em coros de adolescentes, o uso de muitas composições ou arranjos impróprios, do ponto de vista da extensão e tessitura vocais; inadequações na concepção da sonoridade vocal adolescente, ao empregar uma característica sonora de voz adulta no trabalho com vozes juvenis; há problemas, ainda, na qualidade do texto que, por vezes, é poeticamente pobre e não atende à faixa etária, entre outros elementos. Compreendemos que a escolha de repertório apropriado não é uma tarefa fácil para qualquer que seja a faixa etária, no entanto, discutiremos acerca da possibilidade de se estabelecer critérios mínimos que possam ser facilitadores na seleção das peças para um determinado grupo.

Uma parte do segundo estudo consistiu no oferecimento de um curso gratuito, Ferramentas de escrita para coro juvenil, ministrado, no Instituto de Artes da Unesp, em São Paulo, por diferentes professores $^{1}$, nos dias $03,10,17,24$ e 31 de maio de 2019, com duração de 04 horas por dia, com

\footnotetext{
${ }^{1}$ Os professores foram: 03/05 - Prof. Dr. Marcos Mesquita; 10/05 - Prof. Dr. Vitor Gabriel; 17/05 - Prof. Dr. Edmundo Villani-Côrtes; 24/05 - Prof. Lucas Moutinho e Prof. Luis Guilherme Anselmi; 31/05 - Prof. Dr. Carlos Roberto Ferreira Menezes Júnior.
} 
MIGUEL, Fábio. PEDROZO, Willian Gomes, TINEO, Emerson Pereira, PANELLI, Felipe Pillis, PEREZ, Felipe Rodrigues Ferreira, SANTOS, André dos, JACINTO, Maicon Pereira, AMARAL, Regina Célia Corso Marcondes do. Questões acerca do repertório no contexto coral adulto e juvenil. Revista Vórtex, Curitiba, v.8, n.2, p. 1-27, 2020.

carga horária total de 20 horas. O objetivo do curso foi instrumentalizar os participantes ${ }^{2}$ com conhecimentos musicais e vocais que lhes permitissem compor ou arranjar para vozes juvenis no contexto coral, bem como, estimulá-los a submeterem sua composição ou arranjo para o catálogo antes mencionado.

Uma outra parte da pesquisa, Voz juvenil no contexto coral: catálogo de obras em língua portuguesa, foi o levantamento de estudos que abordassem questóes relacionadas aos critérios de seleção de repertório. A ideia foi identificar nos textos, produzidos por diferentes autores, parâmetros para escolha de repertório coral adulto e juvenil, que podem apresentar pontos comuns, mas também podem exibir especificidades próprias a um e outro no que tange a escolha das obras. A seguir sintetizaremos os pontos principais encontrados nas pesquisas levantadas.

\section{Síntese da revisão bibliográfica acerca do tema}

Levantamos textos produzidos por diversos autores (GABRIEL, FIGUEIREDO, ZIELINSKI, SILVA, BRINSON e DEMOREST, EMMONS e CHASE) que trazem concepçóes a respeito do repertório e critérios para sua escolha. Os quatro primeiros autores (GABRIEL, FIGUEIREDO, ZIELINSKI, SILVA) estão ligados ao contexto de coro adulto e os quatro últimos (BRINSON e DEMOREST, EMMONS e CHASE) ao âmbito do coro juvenil. Destacamos que todos os autores estudados, desenvolvem ou desenvolveram trabalho na área de canto coral o que torna suas considerações acerca do tema ainda mais relevantes.

Buscamos, ainda, dissertaçóes e teses, no portal da CAPES (Coordenação de Aperfeiçoamento de Pessoal de Nível Superior) no período de 2015 a 2019, que tratam do tema, bem como nas revistas 3 : OPUS, PER MUSI, MÚSICA HODIE, OUVIROUVER, MÚSICA EM PERSPECTIVA; anais da ABEM (Associação Brasileira de Educação Musical) e ANPPOM (Associação Nacional de Pesquisa e Pós-graduação em Música), no mesmo período anteriormente mencionado. As palavras-chave para busca foram: coral, coro, canto coral, repertório coral, coral

\footnotetext{
${ }^{2}$ Os participantes deveriam atender aos seguintes pré-requisitos: noções de solfejo e teoria musical; noções de harmonia e contraponto.

${ }^{3}$ Essas revistas foram selecionadas em função do seu Qualis: A1, A2, B1 e B4.
} 
MIGUEL, Fábio. PEDROZO, Willian Gomes, TINEO, Emerson Pereira, PANELLI, Felipe Pillis, PEREZ, Felipe Rodrigues Ferreira, SANTOS, André dos, JACINTO, Maicon Pereira, AMARAL, Regina Célia Corso Marcondes do. Questões acerca do repertório no contexto coral adulto e juvenil. Revista Vórtex, Curitiba, v.8, n.2, p. 1-27, 2020.

juvenil, coro juvenil, técnica vocal, preparação vocal.

Nas revistas OPUS, OUVIROUVER e MÚSICA EM PERSPECTIVA não foram encontrados trabalhos relacionados ao tema.

Na revista PERMUSI, foi encontrada uma resenha publicada em 2015, por Débora Andrade, acerca do livro Ampliando o repertório do coro infanto-juvenil: um estudo de repertório inserido em uma nova estética da autora Leila Vertamatti. Andrade aponta que no livro há o questionamento acerca da possibilidade de se trabalhar, no contexto coral, com obras de diferentes estéticas e que não estejam presas aos princípios de uma organização tonal. À época da pesquisa, Leila Vertamatti, por meio de entrevistas com vários regentes de coros infantojuvenis, verificou que o repertório realizado nesses coros era basicamente de cançóes étnicas, música popular brasileira e estrangeira (ANDRADE, 2015, p.345-346).

Na revista MÚSICA HODIE, foram encontrados três trabalhos, sendo um publicado em 2015 e dois em 2016. Somente um, de 2016, tem ligação direta com a questão do repertório. No artigo, Escolhendo o repertório coral: uma tarefa de regentes?, Matheus Cruz Paes de Almeida discute acerca da formação do regente coral nos aspectos da técnica vocal, técnica de regência, técnica de ensaio ou gestão de ensaio, elaboração ou adaptação de arranjos e o papel do regente na escolha do repertório coral. Por meio de estudo de caso com o coral Nossa Voz de Flórida, no Paraná, o autor discorre que o envolvimento dos integrantes do grupo, na escolha do repertório, foi um processo que trouxe motivação e identidade ao coro (ALMEIDA, 2016, p.25). No tópico 2, deste texto, serão feitas mais considerações acerca desse artigo.

Nos anais da ANPPOM, encontramos sete trabalhos, distribuídos da seguinte maneira: 2015 (1), 2016 (1), 2017 (4) e 2018 (1). O texto de 2015, escrito por Fernando Magre e Maria Pires Cabrera Berg, teve como objetivo trazer uma discussão acerca da performance de repertório contemporâneo no coro juvenil. Em 2017, dentre os quatro estudos levantados, somente um tem estreita relação com a questão do repertório. Produzido por Carolina Andrade Oliveira e Susana Cecília Igayra-Sousa, o texto traz uma abordagem do conceito de arranjo coral no repertório brasileiro, a partir da discussão da relação arranjo e composição original e como essas concepções se modificam no contexto popular e erudito. O trabalho de 2018, de Ediel Rocha de Sousa, tratou de fatores influenciadores para aceitação ou rejeição de arranjos corais de música paraense pelos 
MIGUEL, Fábio. PEDROZO, Willian Gomes, TINEO, Emerson Pereira, PANELLI, Felipe Pillis, PEREZ, Felipe Rodrigues Ferreira, SANTOS, André dos, JACINTO, Maicon Pereira, AMARAL, Regina Célia Corso Marcondes do. Questões acerca do repertório no contexto coral adulto e juvenil. Revista Vórtex, Curitiba, v.8, n.2, p. 1-27, 2020.

participantes do coro universitário da UFPA (Universidade Federal do Pará). Nos demais trabalhos, não encontramos relação direta com a temática repertório, sobretudo ao que se refere a concepções e critérios a respeito do tema.

Nos anais da ABEM, foram encontrados dois trabalhos publicados em 2015. Num deles, escrito por Luiz Eduardo Silva e Sérgio Luiz Ferreira de Figueiredo, encontramos uma análise das produçôes referentes à prática coral nos anais de encontros e congressos da ABEM e da ANPPOM disponíveis online no período de 2003-2013. No que se refere ao repertório coral, os autores mencionam que, os trabalhos levantados, "abordam composições para coro, arranjos corais, arranjadores, compositores de músicas para coro e relatos de experiências que descrevem e discutem ações realizadas a partir do repertório coral”, (SILVA e FIGUEIREDO, 2015, p. 9).

No artigo, produzido por Rogéria Tatiane Franchini, a autora apresentou um levantamento das produções científicas brasileiras sobre canto coral com adolescentes no período de 1998 a abril de 2014. No que concerne à questão do repertório, a autora aponta que Leila Vertamatti em sua dissertação de mestrado, Ampliando o repertório do coro infanto-juvenil: um estudo de repertório envolvido numa nova estética, afirma que a prática da música contemporânea no repertório de coro infantojuvenil é pouco difundida, ficando limitada a canções étnicas e música popular brasileira (FRANCHINI, 2015, p. 6). Tal aspecto, também, foi destacado na resenha do livro de título homônimo, escrita por Débora Andrade e publicada na revista PERMUSI, mencionada anteriormente.

Consideramos importante mencionar tais artigos para que o leitor saiba que há dois trabalhos que trazem um estado da arte ${ }^{4}$ referente à pratica coral e coral com adolescentes, com dados levantados dos Anais da ABEM e ANPPOM, anteriores a 2015.

No banco de dissertações e teses da CAPES, encontramos uma dissertação de mestrado, de 2015; duas teses, uma de 2015 e outra de 2017, abordadas, mais adiante, neste texto, no tópico 3.

\footnotetext{
${ }^{4}$ Pesquisa estado da arte é um tipo de estudo que busca verificar como está determinado assunto / tema numa dada área de estudos.
} 
MIGUEL, Fábio. PEDROZO, Willian Gomes, TINEO, Emerson Pereira, PANELLI, Felipe Pillis, PEREZ, Felipe Rodrigues Ferreira, SANTOS, André dos, JACINTO, Maicon Pereira, AMARAL, Regina Célia Corso Marcondes do. Questões acerca do repertório no contexto coral adulto e juvenil. Revista Vórtex, Curitiba, v.8, n.2, p. 1-27, 2020.

\section{Questões relacionadas ao repertório no contexto do coral adulto: apresentação dos critérios indicados por diferentes autores}

A escolha de repertório não é tarefa fácil para qualquer músico, seja cantor, instrumentista ou regente coral. Há muitas variáveis, musicais e extramusicais, de modo que consideramos necessário levantar e discutir esses pontos para que se tenha maior clareza na escolha das peças para as diferentes formações, sobretudo vocais.

Primeiramente, identificamos a necessidade de aprofundar o estudo acerca de questóes relacionadas ao repertório, partindo do contexto coral adulto para posteriormente discutir o assunto no âmbito juvenil.

O repertório pode ser compreendido como uma reunião de obras selecionadas e estudadas para serem apresentadas em diferentes situaçóes e contextos e a diferentes públicos. Portanto, para selecionar obras para um coro é necessário estabelecer critérios. Sem eles, corre-se o risco de escolher obras que não têm a ver com o perfil do grupo e realizar peças que não contribuam para o desenvolvimento artístico-pedagógico dos participantes do coro.

O regente Vitor Gabriel, em seu texto, intitulado Repertório, traz a partir de sua visão e a de outros regentes uma série de itens para seleção de obras para um coro adulto. Ele orienta para que sejam escolhidas peças adequadas às capacidades técnico-estéticas dos cantores; sugere fazer um repertório menos ousado, mas criativo e que seja interpretado de maneira musical; propõe considerar as características de cada grupo; indica, ainda, diversificar o repertório: variar o gênero, estilo, forma e período histórico e organizar o repertório selecionado para os ensaios e apresentaçóes (GABRIEL, 2018, p. 4-5).

De acordo com Gabriel, o regente Robert L. Garretson parametriza a escolha do repertório levando em conta: o texto; a qualidade artística da música e sua relação com o texto; se o repertório selecionado atende as necessidades e interesses do grupo para o qual as peças foram escolhidas; questốes relacionadas às limitaçóes físicas dos cantores; às tessituras de cada naipe; como os extremos da tessitura são alcançados em cada naipe; à condução das partes vocais; qualidade do arranjo (mantém a autenticidade do estilo musical da peça de origem); se a música selecionada justifica o tempo de ensaio para prepará-la; variedade de tipos e estilos musicais (GABRIEL, 2018, 
MIGUEL, Fábio. PEDROZO, Willian Gomes, TINEO, Emerson Pereira, PANELLI, Felipe Pillis, PEREZ, Felipe Rodrigues Ferreira, SANTOS, André dos, JACINTO, Maicon Pereira, AMARAL, Regina Célia Corso Marcondes do. Questões acerca do repertório no contexto coral adulto e juvenil. Revista Vórtex, Curitiba, v.8, n.2, p. 1-27, 2020.

p. 10-11).

O regente Carlos Alberto Figueiredo, em seu texto intitulado: Reflexóes sobre aspectos da prática coral traz os seguintes critérios para escolha de repertório: o prazer estético que a música desperta no regente ou no coro; a qualidade do texto literário; a obra como fator de crescimento para o regente e o coro; as necessidades na elaboração de um programa; a obra como veículo de prestígio para o regente ou o coro e o seu impacto no meio musical; escolher obras que estejam dentro da capacidade do coro e do regente; saber contornar situaçóes em que o repertório é escolhido por outros (escola, empresa...) (FIGUEIREDO, 2010, p. 25-26).

O regente norte-americano, Richard Zielinski, propõe os seguintes critérios para escolha de repertório: duração da peça; alcance vocal e tessitura de cada voz; dificuldade de linguagem; complexidades rítmicas, instrumentação, à capela versus com acompanhamento; dificuldades do acompanhamento de piano e divises presentes na parte vocal (ZIELINSKI, 2005, p.45, tradução nossa). Sugere, ainda, fazer algumas perguntas para selecionar o repertório: as obras selecionadas ajudarão o meu coro a desenvolver uma melhor produção vocal? Que música moderna/contemporânea, de compositor que esteja vivo, estou programando? Eu tenho as vozes necessárias para executar as obras selecionadas? Estou selecionando essas obras corais somente porque gosto delas? Eu tenho o tempo de ensaio para preparar essa música? O meu pianista acompanhador consegue tocar essa música? Existe variedade de estilo suficiente, e essas seleçôes se encaixam em todo ano letivo? A música é apropriada para ocasião na qual ela será executada? As obras selecionadas têm uma mensagem positiva e apropriada? (ZIELINSKI, 2005, p. 46).

A partir da dissertação de Luiz Eduardo Silva, intitulada: $O$ ensino e a aprendizagem da técnica vocal em corais amadores a partir da concepção de regentes e cantores, na qual ele entrevistou quatro regentes corais de Florianópolis, é possível identificar como eles concebem o repertório para os coros que estão sob sua direção. O regente 1 seleciona o repertório de acordo com as necessidades litúrgicas da igreja católica a qual o coro está vinculado (SILVA, 2017, p. 70); o regente 2 seleciona arranjos que valorizam a forma coral a partir do seu próprio gosto musical e considera que no repertório do coro deve haver músicas de diferentes épocas e estilos, tais como peças à capela, música renascentista e música popular brasileira, músicas a uma, duas e quatro vozes (SILVA, 2017, p. 78); o regente 3, utiliza arranjos de música popular brasileira e, também, produz arranjos seus para o 
MIGUEL, Fábio. PEDROZO, Willian Gomes, TINEO, Emerson Pereira, PANELLI, Felipe Pillis, PEREZ, Felipe Rodrigues Ferreira, SANTOS, André dos, JACINTO, Maicon Pereira, AMARAL, Regina Célia Corso Marcondes do. Questões acerca do repertório no contexto coral adulto e juvenil. Revista Vórtex, Curitiba, v.8, n.2, p. 1-27, 2020.

coro (SILVA, 2017, p. 89); o regente 4, seleciona as peças de acordo com as apresentações assumidas, divididas entre as festividades nas igrejas e capelas do município e os eventos cívicos da prefeitura. Grande parte do repertório é voltada para música religiosa e litúrgica. Este regente também procura repertório que proporcione desenvolvimento vocal para os cantores (SILVA, 2017, p. 98).

No artigo, da revista MÚSICA HODIE, escrito por Matheus Cruz Paes de Almeida denominado: Escolhendo repertório coral: uma tarefa de regentes? temos um estudo de caso que trata da participação dos coristas na escolha do repertório feita mediante a aplicação de um questionário por meio do qual buscou-se saber que repertório os participantes gostariam que fosse executado no coro. Segundo o autor, depois de analisados os questionários, algumas peças foram incluídas para serem cantadas no grupo (ALMEIDA, 2016, p. 32). De acordo com Almeida, essa ação que colocou os integrantes do coro como participantes no processo de escolha do repertório, os motivou a não faltar no ensaio, a chegar no horário, e os fez, também, querer cantar cada vez mais as peças que faziam parte de suas vivências.

Em suma, não há um modelo exato para escolha de repertório. Contudo, a partir do que foi esboçado anteriormente, é possível criar algumas aproximaçôes e perceber critérios comuns propostos pelos autores enunciados.

Em seguida apresentaremos nossa visão acerca do assunto, a partir de uma análise dos critérios para escolha do repertório definidos pelos autores antes mencionados.

\subsection{Cotejamento dos critérios para seleção de repertório, no âmbito do coro adulto, apresentados por diferentes autores}

A partir de um cotejamento entre os critérios para seleção de repertório coral, enunciados anteriormente pelos autores citados, podemos pensar nos seguintes parâmetros para escolha de repertório coral no contexto de vozes adultas:

- Nível de percepção auditiva e de leitura musical (quando for o caso). As obras corais possuem diferentes graus de dificuldade, de modo que elas exigem níveis diferenciados de percepção auditiva e leitura musical. A complexidade da linguagem empregada pelo 
MIGUEL, Fábio. PEDROZO, Willian Gomes, TINEO, Emerson Pereira, PANELLI, Felipe Pillis, PEREZ, Felipe Rodrigues Ferreira, SANTOS, André dos, JACINTO, Maicon Pereira, AMARAL, Regina Célia Corso Marcondes do. Questões acerca do repertório no contexto coral adulto e juvenil. Revista Vórtex, Curitiba, v.8, n.2, p. 1-27, 2020.

compositor na peça coral pode facilitar ou dificultar a percepção auditiva e leitura dos cantores. Um grupo que está acostumado a cantar peças tonais, provavelmente, sentirá maior dificuldade para cantar obras que estejam inseridas em outros sistemas musicais, tais como, o atonal, bitonal, entre outros.

- Afinação. Algumas peças serão mais fáceis ou difíceis de afinar, dependendo da textura; se for à capela ou com acompanhamento. A afinação vocal pode ser influenciada, ainda, pela maneira como cada linha é construída e como se relaciona com as demais. A complexidade da linguagem pode, ainda, influenciar no controle e precisão da afinação.

- Conhecimento histórico-estilístico. As obras corais estão inseridas em diferentes períodos da história da música, com consequentes desdobramentos estilísticos, que exigem do regente e dos cantores, um domínio do vocabulário musical estabelecido em cada época, para que a obra seja concebida dentro das características musicais, estruturadas pelo compositor em sua escritura musical. Deve-se levar em conta, o gênero, a forma, a textura, o contraponto, a harmonia, a melodia, o ritmo, o texto, o ethos que configura o modo de expressão e apresentação de tais obras. Por exemplo, se o regente e coro não possuírem noçôes básicas do que é uma Frotolla ${ }^{5}$, ao realizar com o seu coro a peça El Grilo de Josquin Des Prez, a farão, provavelmente, fora de estilo.

- Musicalidade. Algumas obras corais podem ser fáceis do ponto de vista da percepção auditiva, da leitura, mas não são, na musicalidade, na expressividade necessária para o controle da dinâmica, do fraseado, das mudanças agógicas, entre outros parâmetros. Por exemplo, a observação da indicação de sotto voce, no início da peça Ave Verum de Mozart, é essencial para uma boa expressão vocal e musical. No entanto, a maioria dos coros, sobretudo, amadores, não seguem essa indicação. O efeito de sotto voce, exige do cantor

\footnotetext{
${ }^{5}$ Tipo de canção italiana de fins do século XV e princípio do XVI mais importante depois do madrigal. De poesia leve e sem forma fixa, é geralmente estrófica, silábica, a quatro vozes mistas com a melodia principal na voz aguda, homofônica e com harmonias diatônicas simples e estrutura rítmica bem marcada. Era um termo genérico que englobava alguns subtipos como a barzelletta, o capitolo, a terza rima, o strambotto e a canzone. Nas ediçốes de época o texto está colocado apenas no soprano, sugerindo que as demais vozes fossem tocadas. É precursora do madrigal italiano e influenciou a chanson francesa. Apesar de sua simplicidade e popularidade a Frottola não era uma forma de música popular ou folclórica., pois derivava das Cortes italianas (especialmente de Mantova, Urbino e Ferrara). É a precursora do Madrigal italiano (GABRIEL, 2014, p.68)
} 
MIGUEL, Fábio. PEDROZO, Willian Gomes, TINEO, Emerson Pereira, PANELLI, Felipe Pillis, PEREZ, Felipe Rodrigues Ferreira, SANTOS, André dos, JACINTO, Maicon Pereira, AMARAL, Regina Célia Corso Marcondes do. Questões acerca do repertório no contexto coral adulto e juvenil. Revista Vórtex, Curitiba, v.8, n.2, p. 1-27, 2020.

controle da respiração e da ressonância para que ele seja produzido adequadamente.

- Nível técnico-vocal. Refere-se a aspectos tais como: emissão vocal, registro vocal, capacidade respiratória, dicção, propriocepção, tessitura de cada voz. Ao escolher o repertório, o regente precisa levar em conta a qualidade da emissão dos seus cantores, para saber se serão atendidas as necessidades sonoras da obra selecionada. Um grupo cuja emissão vocal é centrada numa ressonância laríngea, como uma sonoridade "aberta e rasgada”, terá que buscar outra qualidade vocal para cantar um repertório que necessite de uma emissão vocal, por exemplo, com ressonância vocal alta ${ }^{6}$ e vice-versa. Deve-se considerar em cada peça, qual o nível necessário para a percepção do controle dos diferentes registros vocais, que envolvem a qualidade sonora da voz na região grave, média e aguda, bem como, de que modo é feita a transição entre essas regiões. É necessário, também, identificar como está o controle da respiração dos cantores, para que eles possam fazer as frases musicais, exigidas no repertório, com tranquilidade na administração do fluxo de ar. O repertório precisa estar conectado ao trabalho de técnica vocal e preparação vocais, pois o aprimoramento vocal do grupo terá resultados na qualidade musical e artística das peças selecionadas.

- Aspectos melódicos, harmônicos e contrapontísticos que podem facilitar ou dificultar a execução da peça. As diferentes texturas musicais no repertório coral podem oferecer facilidades ou dificuldades de execução, dependendo do que o coro está acostumado a cantar. Há coros que não estão habituados a cantar peças com textura contrapontística, de modo que o regente precisa saber como irá trabalhar para que os cantores possam se sentir mais confortáveis e confiantes na execução de repertório com essa textura.

- Considerar a quantidade de coristas por naipe. De acordo com a sonoridade de cada obra, é necessário ter um coro equilibrado, com uma quantidade de cantores por naipe que não prejudique a sonoridade da peça escolhida. Por exemplo, um coro com um número maior de homens e uma quantidade menor de vozes femininas poderá ter dificuldades para

\footnotetext{
${ }^{6}$ Atinge uma localização bem alta na faringe, percorrendo todo o tubo faríngeo e produzindo sensaçốes vibratórias por todo o crânio. O alongamento faríngeo é pré-requisito fundamental para o foco alto. Esse tipo de ressonância é mais comum ao estilo de canto chamado lírico/erudito.
} 
MIGUEL, Fábio. PEDROZO, Willian Gomes, TINEO, Emerson Pereira, PANELLI, Felipe Pillis, PEREZ, Felipe Rodrigues Ferreira, SANTOS, André dos, JACINTO, Maicon Pereira, AMARAL, Regina Célia Corso Marcondes do. Questões acerca do repertório no contexto coral adulto e juvenil. Revista Vórtex, Curitiba, v.8, n.2, p. 1-27, 2020.

realizar, de modo equilibrado, peças corais no padrão SATB uma vez em que determinadas regiões as vozes masculinas podem produzir maior volume em comparação às vozes das mulheres, de modo a comprometer o equilíbrio sonoro entre os naipes. Em muitos cursos de música ${ }^{7}$, nas universidades, encontramos dificuldade na realização, de modo equilibrado, repertório SATB, pois o número de vozes masculinas é muito maior em comparação ao número de vozes femininas. Nos coros fora da universidade, o desequilíbrio numérico ${ }^{8}$ ocorre de outra maneira pois, geralmente, a quantidade de vozes femininas é maior do que o número de vozes masculinas.

- Sonoridade vocal, exigidas pelo repertório. A sonoridade das obras corais varia de acordo com o período histórico e estilo. Portanto, o regente deve considerar se os cantores do coro sob sua orientação, estão preparados musical e vocalmente, ou poderão ser conduzidos a diferenciar e cantar peças que exigem variadas sonoridades. Por exemplo, um arranjo de música popular brasileira para coro, não deve ser cantado com a mesma sonoridade vocal de uma peça do período romântico e vice-versa.

- Selecionar o repertório com vistas ao desenvolvimento técnico-musical do grupo a curto, médio e longo prazo. O regente deve se perguntar ao selecionar repertório para o seu coro: quais benefícios vocais e musicais os cantores terão ao estudar o repertório proposto? Qual a herança vocal e musical que será deixada ao coro? Em 2014, quando realizamos, com o Coro de Câmara' do Instituto de Artes da Unesp, a Missa Lord Nelson de Haydn, percebemos o ganho vocal dos cantores e cantoras, durante os ensaios. Eles ganharam na ampliação da tessitura e, também, na melhora da mistura vocal entre os integrantes do naipe e entre os demais naipes. Os benefícios vocais ficaram evidentes, ainda, em outras peças trabalhadas naquele ano.

- Duração e frequência dos ensaios. O regente deve levar em conta quantos ensaios serão

\footnotetext{
${ }^{7} \mathrm{Na}$ disciplina Performance de repertório de música brasileira à capela, ministrada no Instituto de Artes da Unesp em 2019, o número de alunos por naipe foi: sopranos (07); mezzo (05); tenores (14); baixo/barítono (09)

${ }^{8}$ Não há, até o momento, estudos científicos que comprovam essa afirmação que é realizada com base em minha experiência com coros fora da universidade e por relatos orais de outros regentes corais acerca desse fenômeno.

${ }^{9}$ Esse coro é uma disciplina obrigatória do curso de música no Instituto de Artes da Unesp. Os integrantes do coro são alunos do curso de canto, instrumento, licenciatura em música e regência. A quantidade de estudantes por naipe, nesse ano, foi: soprano (12); mezzo (08); tenor (11), barítono/baixo (08).
} 
MIGUEL, Fábio. PEDROZO, Willian Gomes, TINEO, Emerson Pereira, PANELLI, Felipe Pillis, PEREZ, Felipe Rodrigues Ferreira, SANTOS, André dos, JACINTO, Maicon Pereira, AMARAL, Regina Célia Corso Marcondes do. Questões acerca do repertório no contexto coral adulto e juvenil. Revista Vórtex, Curitiba, v.8, n.2, p. 1-27, 2020.

necessários para preparar a peça escolhida, observando se a duração do ensaio é cabível para o grau de dificuldade das peças selecionadas, bem como se a frequência semanal dos ensaios é suficiente para se trabalhar tais obras.

- Variar gênero, forma, estilo ou período histórico na escolha do repertório para o coro. Não é interessante para a formação dos cantores do coro, bem como para o seu desenvolvimento vocal, cantar repertório sem variar, em geral, o gênero. No Brasil, percebemos, por muitas vezes, que os coros amadores têm uma tendência a focalizar o seu repertório em arranjo de música popular brasileira, deixando de lado obras de outros gêneros e estilos que poderiam agregar benefícios vocais e musicais aos participantes do grupo e, também, novas possibilidades de escuta e fruição musical ao público.

- Qualidade musical e do texto literário. Isto está relacionado a qualidade técnica e estética da peça, a relação texto/música, condução vocal, elementos estruturais e forma.

- Características do coro e seus objetivos. Por exemplo, um coro formado para atender as necessidades litúrgicas em uma igreja protestante dificilmente terá em seu repertório arranjo de música popular brasileira ${ }^{10}$. Contudo, poderá ter em seu repertório arranjos de música com textos bíblicos, com características estilísticas dos arranjos de música popular brasileira, no que se refere por exemplo, à sonoridade vocal, à textura, à estrutura rítmica, à condução harmônica e ao acompanhamento instrumental.

- Locais de apresentação do coro e o público que ouvirá o repertório. Por exemplo, dependendo da natureza do evento, não é adequado que o coro cante música profana ou música sacra.

\footnotetext{
${ }^{10}$ Essa afirmação é fruto de mais de 20 anos de experiência, do autor deste texto com trabalho coral adulto, no contexto de igrejas protestantes em São Paulo e na grande São Paulo.
} 
MIGUEL, Fábio. PEDROZO, Willian Gomes, TINEO, Emerson Pereira, PANELLI, Felipe Pillis, PEREZ, Felipe Rodrigues Ferreira, SANTOS,

André dos, JACINTO, Maicon Pereira, AMARAL, Regina Célia Corso Marcondes do. Questões acerca do repertório no contexto coral adulto e juvenil. Revista Vórtex, Curitiba, v.8, n.2, p. 1-27, 2020.

\section{Questóes relacionadas ao repertório no contexto do coral juvenil: ${ }^{11}$ apresentação dos critérios indicados por diferentes autores}

Nesta parte abordaremos como são tratados, a partir de alguns autores, os critérios relacionados ao repertório no contexto do coro juvenil, buscando ao final sintetizar os pontos para escolha de repertório nessa configuração coral.

Iniciamos este trecho, pensando acerca de uma possível configuração coral juvenil. Nos anais do SIMPOM (Simpósio Brasileiro de Pós-graduandos em Música) de 2018, encontramos um trabalho, da Patrícia Costa, intitulado As características de um coro juvenil, no qual nos deparamos com a conceituação de coro juvenil a partir de quatro enfoques facilitadores: faixa etária, escolaridade, tessitura vocal e configuração coral. Faixa etária: 14 a 18 anos; escolaridade no Brasil: 1‥ , 2‥ e 3‥ anos do ensino médio; tessituras: soprano (Mi3-Fá4) $)^{12}$, Alto (Lá2-Dó4), Tenor (Ré2Mi3), Baixo (Si1-Dó3); configuração coral: vozes mistas (S-A-T-B) (COSTA, 2018, p. 781-785). Essa conceituação, embora não seja única, poderá auxiliar o leitor a visualizar, sobretudo no contexto brasileiro, para que tipo de coro juvenil as questóes de seleção de repertório serão discutidas.

Patrícia Costa, em sua tese de doutorado, enfatiza que o repertório tem função aglutinadora e regularizadora, segundo ela é um elemento para atrair e reter cantores juvenis (COSTA, 2017, p. 51). Traz, ainda, critérios técnicos para escolha de repertório: número de cantores; características da formação dos naipes; o nível de desenvolvimento vocal/musical dos participantes; qualidade vocal do grupo, capacidade de realização de determinados graus de dificuldade; perfil social do coro e seus componentes; metas e objetivos do coro; conhecimento do regente sobre obras corais (COSTA, 2017, p. 58). Destaca, também, algumas especificidades para seleção de repertório para coro juvenil, a saber: singularidades da faixa etária; tessitura das vozes juvenis; a necessidade de fazer uma anamnese do grupo; observar as necessidades dos adolescentes no período de muda vocal; adequação de repertório ao grupo; texto/tema das composições; diversidade do repertório (COSTA,

\footnotetext{
${ }^{11}$ Não será foco desse artigo discutir acerca da faixa etária e características de um coro juvenil, para isso o leitor poderá consultar a tese de doutorado da Patrícia Costa e Ana Lúcia Gaborim, por meio quais é possível ter informações a esse respeito.

${ }^{12} \mathrm{O}$ sistema de numeração de oitavas utilizado é o francês.
} 
MIGUEL, Fábio. PEDROZO, Willian Gomes, TINEO, Emerson Pereira, PANELLI, Felipe Pillis, PEREZ, Felipe Rodrigues Ferreira, SANTOS, André dos, JACINTO, Maicon Pereira, AMARAL, Regina Célia Corso Marcondes do. Questões acerca do repertório no contexto coral adulto e juvenil. Revista Vórtex, Curitiba, v.8, n.2, p. 1-27, 2020.

2017, p. 60-63). Escreve ainda, acerca do objetivo do repertório: pedagógico ou performático.

Tanto Patrícia Costa (2017, p. 63-67) quanto Ana Lúcia Gaborim (2015, p. 137) mencionam em suas respectivas teses de doutorado, que é possível realizar repertório erudito e contemporâneo com coro juvenil. Costa, sugere, inclusive, o uso de arranjos de música popular brasileira, sobretudo a partir de músicas previamente conhecidas pelos participantes do grupo (2017, p. 68-70). Ana Lúcia Gaborim, destaca a necessidade do regente selecionar um repertório que atenda às especificidades do grupo, motive os participantes e esteja comprometido com o seu desenvolvimento crítico, estético, vocal e $\operatorname{artístico~}^{13}$ (2015, p. 133).

Juliana Damaris de Santana Paziani, em sua dissertação de mestrado, destaca a importância de se utilizar obras escritas originalmente para a formação - infantojuvenil, para que se possa evitar o uso inadequado de arranjos e adaptações de canções da tradição oral, MPB, canções étnicas (2015, p.142). Enfatiza, ainda, a necessidade de pesquisa de repertório específico para essa formação, além de reiterar que o regente pode criar/compor peças para o grupo que está sob sua direção ${ }^{14}(2015$, p.143). Assim, reiteramos com este critério, que é necessário pesquisar repertório específico para a formação de coro juvenil, abrangendo peças, por exemplo, a uma, duas e três vozes no padrão SAB em diferentes texturas. $\mathrm{O}$ formato $\mathrm{SAB}$ tem sido o mais indicado para vozes juvenis, uma vez que coloca os meninos num único naipe, utilizando uma tessitura confortável, em geral, Ré2-Ré3, ao invés de usar o padrão SATB, que pode extrapolar a tessitura possível para os meninos na adolescência, sobretudo aqueles que estão na fase da muda vocal.

Emmons e Chase em seu livro intitulado, Prescriptions for choral excelence: Tone, text, dynamic leadership, apresentam as seguintes consideraçôes para escolha de repertório para vozes juvenis: parâmetros musicais não são os únicos critérios para escolha de repertório para vozes mais jovens; a saúde vocal deve fazer parte da tomada de decisão do regente coral; conhecimento do status vocal de todos os cantores; consideração de quais peças irão construir e não prejudicar vozes jovens; escolhas de músicas que se adaptem às vozes, em vez de fazer as vozes se encaixarem nas músicas; avaliação de quão agudo é requerido cantar; pesquisa da tessitura ideal de canto da faixa etária dos cantores;

\footnotetext{
${ }^{13}$ Embora o trabalho trate de coro infantojuvenil, esse critério pode ser plenamente adaptado ao contexto de coro juvenil e, também, para o âmbito do coro adulto.

${ }^{14}$ Embora o trabalho trate de coro infantojuvenil, esse critério pode ser plenamente adaptado ao contexto de coro juvenil, bem como ao âmbito do coro adulto.
} 
MIGUEL, Fábio. PEDROZO, Willian Gomes, TINEO, Emerson Pereira, PANELLI, Felipe Pillis, PEREZ, Felipe Rodrigues Ferreira, SANTOS, André dos, JACINTO, Maicon Pereira, AMARAL, Regina Célia Corso Marcondes do. Questões acerca do repertório no contexto coral adulto e juvenil. Revista Vórtex, Curitiba, v.8, n.2, p. 1-27, 2020.

consideraçôes acerca da tessitura, extensão, níveis de dinâmica e duração do tempo que esses parâmetros estarão em uso, ao tentar atender o desejo dos cantores e seus pais de realizar repertório do teatro musical e música pop (2006, p.167, tradução nossa).

Brinson e Demorest, em seu livro, Choral Music: methods and materials, trazem as seguintes consideraçóes acerca do repertório: os estudantes devem aprender sobre música por meio do repertório escolhido pelo regente (2014, p.93, tradução nossa); sugere balancear o grau de dificuldade técnica das peças - uma ou duas peças difíceis tecnicamente, e uma ou duas peças fáceis tecnicamente - para que, ao serem escolhidas somente peças tecnicamente difíceis, não se use todo o tempo do ensaio somente para resolver aspectos básicos das obras (altura e ritmo), deixando pouco tempo para tratar de aspectos musicais avançados da arte coral (2014, p.94).

Os autores consideram importante escolher um repertório variado, incluindo músicas de vários períodos da História da Música, tanto repertório “canônico” quanto peças corais contemporâneas, jazz, música de outras culturas, arranjos de músicas "folclóricas”, spiritual, Broadway, pop e música gospel.

Enfatizam que é importante cantar repertório em outros idiomas, porque possibilita o contato com outras línguas que não a materna e, ainda, tem-se a oportunidade de desenvolver a dicção. Contudo, alertam que, cantar em outras línguas requererá aproximadamente $20 \%$ a mais, de tempo, no ensaio para dominar a peça (BRINSON, DEMOREST, 2014, p. 95). Tratam, também, da escolha de modo balanceado, de peças à capela e obras com acompanhamento de instrumentos além do piano.

Discorrem, também, que o regente precisa mostrar entusiasmo com o repertório coral escolhido, para entusiasmar os participantes com as peças escolhidas. Os autores sugerem, ainda, que o regente amplie o seu gosto musical para que possa incluir, no repertório coral, peças com variedade de estilo, de diferentes culturas, épocas, idiomas e compositores (BRINSON, DEMOREST, 2014, p.96).

De acordo com os autores, uma grande técnica para motivar e engajar os alunos no aprendizado musical é envolvê-los no processo de seleção musical. Apontam que uma forma de fazer isso é escolher várias seleçôes de músicas de qualidade adequadas para o coral. Depois de cantar cada peça ou ouvir gravações, os alunos poderão votar em qual das peças gostariam de aprender e 
MIGUEL, Fábio. PEDROZO, Willian Gomes, TINEO, Emerson Pereira, PANELLI, Felipe Pillis, PEREZ, Felipe Rodrigues Ferreira, SANTOS, André dos, JACINTO, Maicon Pereira, AMARAL, Regina Célia Corso Marcondes do. Questões acerca do repertório no contexto coral adulto e juvenil. Revista Vórtex, Curitiba, v.8, n.2, p. 1-27, 2020.

executar. Segundo os autores, desta maneira, os alunos entenderão que têm parte na escolha da música. Consideram, também, uma oportunidade para que eles aprendam acerca da avaliação da música e da performance musical, principalmente se o regente conversar com eles acerca das várias seleçóes e dos motivos por que preferem uma peça à outra. Brinson e Demorest, propóem que se abra o acesso, aos alunos, à biblioteca coral para que sejam envolvidos ainda mais ativamente na seleção de repertório. Acreditam que é uma ótima maneira de começar a fazer com que os alunos pensem no repertório apropriado para pequenos grupos que eles possam criar por conta própria (2014, p.96-97).

Há diversos outros critérios que Brinson e Demorest colocam como parâmetros para seleção de repertório, a saber: extensão e tessitura de cada parte, com diversas consideraçóes de como são cantadas as vogais nas notas que ocorrem no extremo agudo ou grave da voz em cada naipe; a duração e dinâmica das notas extremas, entre outros aspectos. Discorrem, ainda, da qualidade literária do texto; da necessidade de balancear repertório sacro e secular; o cuidado com o acompanhamento nos ensaios e concertos; cuidado com a escolha de arranjos e transcriçóes; selecionar músicas para o repertório coral de várias culturas; observar o tamanho do coro para a escolha do repertório; verificar a maturidade vocal do coro; considerar a textura das peças como critério de escolha. Por exemplo, consideram que o uníssono é uma excelente ferramenta para construir o tom coral e a mistura vocal, bem como é uma oportunidade para explorar a expressividade no canto. No entanto, alertam que cantar uníssono em oitavas pode ser quase impossível para coros com meninos cujas vozes estejam mudando. Sugerem que, se a extensão da melodia for muito ampla, escolher um trecho numa região mais limitada para a prática do uníssono. Brinson e Demorest consideram que, na música polifônica simples, a natureza melódica das linhas vocais imitativas pode ser mais fácil de ser entendida por cantores jovens e inexperientes, mais do que harmonias de bloco, muitas vezes não melódicas encontradas na música homofônica. Os autores observam, ainda, que ao escolher repertório para o coro é necessário considerar o público potencial (2014:97-105) 


\subsection{Cotejamento dos critérios para seleção de repertório, no contexto do coro juvenil, apresentados por diferentes autores}

Ao fazermos um cotejamento entre os parâmetros para escolha de repertório para coro juvenil, a partir dos autores antes mencionados, podemos notar uma convergência na seguinte direção (MIGUEL, UTSUNOMIYA, 2015, p. 5-6):

- O repertório precisa envolver emocionalmente os integrantes do coro juvenil e ser entusiasmante para o regente: educação e envolvimento! (Quais são os objetivos ao escolher o repertório? Aumentar a bagagem cultural e educacional? Abordar algum tema específico? É preciso "incluir peças que apresentam algum desafio para a criança ${ }^{15}$, que sejam interessantes e que contribuam para sua formação cultural” (SCHIMITI, 2003, p. 4). Reiteramos que a afirmação de Figueiredo, pode ser aplicada ao âmbito do coro juvenil,

Cantar em coro deveria ser sempre uma experiência de desenvolvimento e crescimento, individual e coletivo: o desenvolvimento da musicalidade e da capacidade de se expressar através de sua voz; a possibilidade de vir a executar obras que tocam tanto no cognitivo quanto no coração, ensejando o crescimento intelectual e afetivo do cantor e de outros agentes envolvidos; o desenvolvimento da sociabilidade e da capacidade de exercer uma atividade em conjunto, onde existem os momentos certos para se projetar e se recolher, para dar e receber. (FIGUEIREDO, 2003, p. 4)

- É necessário desafiar o coral a sair da zona de conforto, tomando cuidado para não frustrar os participantes. Embora esse cuidado, também, seja necessário no coral adulto, consideramos que no contexto do coro juvenil a questão é mais delicada, pois jovens cantores que se frustram com a prática do canto coral, poderão não se interessar pelo resto da vida por uma nova experiência coral. Escolher uma ou duas músicas difíceis e uma ou duas que possam ser apresentadas com perfeição e facilidade. Sugerimos que sejam escolhidas peças fáceis, de grau de dificuldade médio e peças difíceis. As peças fáceis farão

\footnotetext{
${ }^{15}$ No caso desse texto "do adolescente”.
} 
com que o coro se sinta sempre cantando; as peças mais difíceis cumprirão o papel de ampliar a zona de conforto do coro.

- Escolher estilos diferentes, nos ensaios e na performance (músicas de períodos diferentes da história, música contemporânea, músicas em latim, italiano, a capela, acompanhados por piano, acompanhados por outros instrumentos. A variação de acompanhamento instrumental permite que o adolescente aumente seu conhecimento de timbres e aperfeiçoa suas habilidades de afinação. Lembramos que o preparo/ensaio de repertório em línguas estrangeiras, demanda cerca de $20 \%$ a mais de tempo. Embora Brinson e Demorest não apresentaram justificativas para o fato de se gastar mais tempo no repertório em línguas não maternas, podemos conjecturar que isso se deva, entre outras razôes, pelas especificidades fonéticas de cada idioma, bem como a familiaridade dos cantores com as diferentes línguas que possam ser utilizadas no repertório coral, além das necessidades de ajustes vocais do idioma da fala para o canto no contexto de cada peça musical.

- Texto: variedade de assuntos e temas, lembrando que textos em língua estrangeira trazem possibilidades de outros timbres vocais. Outras questôes em relação a este tópico podem ser consideradas: $\mathrm{O}$ texto da música por si só pode ser considerado como um texto importante? O coral se identifica com a mensagem do texto? É um conteúdo de interesse?).

- Desenvolver a habilidade de cantar. O repertório precisa desenvolver o potencial de canto dos integrantes do coro.

- Quantidade de integrantes no coral. Isso será importante para se pensar o volume requerido nas diferentes obras, bem como o equilíbrio entre os naipes, quando o coro juvenil cantar peças no padrão SAB. É preciso lembrar que as vozes dos (as) cantores (as) de coros juvenis, não possuem a mesma projeção e volume, das vozes de cantores (as) de coros adultos.

- Verificar quais são os intervalos melódicos mais fáceis e os mais difíceis para o grupo cantar. Em geral, as pessoas tendem a ter maior dificuldade nos intervalos de trítono, intervalos descendentes e mais amplos, tais como, 6a․ maior ou menor; 7a. maior ou 
menor; 8ạ. justa. Isto se dá, entre outras razões, porque a voz é um instrumento que se adapta melhor a execução de graus conjuntos. Outro motivo está relacionado a percepção e sensação auditiva dos intervalos descendentes que, em geral, as pessoas não afinam com precisão em comparação às notas em movimento melódico ascendente.

- Privilegiar peças com graus conjuntos. O uníssono é a textura mais indicada para grupos iniciantes. De acordo com Brinson e Demorest, conforme mencionado na página 16, deste artigo, o uníssono é uma excelente estratégia para construir o tom coral e a mistura vocal, bem como é uma oportunidade para explorar a expressividade no canto.

- Ser cuidadoso e criativo na elaboração da ordem das peças para o concerto/apresentação. Pensar em critérios, como por exemplo: que peça vai abrir o concerto? que peça vai fechar o concerto?; andamento das músicas; tonalidade; caráter da obra; dificuldades e facilidades vocais da obra; acústica do local; a obra é sacra ou profana?; à capela ou com acompanhamento; tem solo?

- Análise da partitura: verificar qual a vogal emitida na nota mais aguda da peça e a sua duração; verificar se essa nota aguda está precedida de um salto; se está apoiada por outros naipes; se, na peça, é apenas uma nota aguda ou são frases ou períodos na região mais aguda; e ainda, verificar se a dinâmica está combinada com notas fora da zona de conforto pois podem apresentar dificuldades na execução. Este critério é de suma importância, principalmente, ao se considerar as vozes em muda vocal, as quais apresentam certas dificuldades para a emissão vocal em determinadas regióes do registro da voz, dependendo do fonema, da duração da nota, do desenho melódico, entre outros fatores.

- Ter boas edições da partitura (se for o caso) que será utilizada no ensaio. A observação deste critério pelo regente coral contribuirá para que não se perca tempo no ensaio com correções de notas, textos, e dinâmica ilegíveis. 
MIGUEL, Fábio. PEDROZO, Willian Gomes, TINEO, Emerson Pereira, PANELLI, Felipe Pillis, PEREZ, Felipe Rodrigues Ferreira, SANTOS,

André dos, JACINTO, Maicon Pereira, AMARAL, Regina Célia Corso Marcondes do. Questões acerca do repertório no contexto coral adulto e juvenil. Revista Vórtex, Curitiba, v.8, n.2, p. 1-27, 2020.

\section{Pontos de convergência nos parâmetros para escolha de repertório no contexto do coral adulto e juvenil e pontos específicos ao contexto coral juvenil}

Ao estabelecermos um comparativo entre os critérios mencionados, pelos autores, para seleção de repertório, no contexto do coral adulto e juvenil, podemos agrupá-los em dois grandes grupos: critérios técnicos e critérios gerais, os quais apresentaremos de modo sintético, a seguir. Os critérios técnicos estão relacionados às condiçôes técnico-vocais e musicais necessárias para realização das músicas selecionadas para o grupo. Os critérios gerais dizem respeito a outros elementos extramusicais do repertório, no contexto da atividade coral. Ambos os critérios se relacionam no processo de escolha de repertório para um determinado grupo.

Os pontos de convergência nos parâmetros para escolha de repertório para coro adulto e juvenil são:

- Critérios técnicos: extensão e tessitura de cada naipe; maturidade vocal dos cantores; quantidade de cantores por naipe; quais as contribuiçóes vocais e musicais o repertório trará aos cantores; duração da peça; frequência dos ensaios; complexidades rítmicas, melódicas, harmônicas, contrapontísticas; o tipo de acompanhamento ou se é à capela; variar gênero, forma, estilo ou período histórico na escolha do repertório para o coro; balancear o grau de dificuldade técnica das peças; escolher repertório em outros idiomas; escolher o repertório levando em conta a qualidade do texto e sua relação com a música; escolher repertório que desenvolva a habilidade de cantar.

- Critérios gerais: características de cada grupo; objetivos do coro; necessidades e interesses do grupo; locais de apresentação e público potencial; escolher um repertório criativo e que possa ser realizado de modo musical; escolher repertório que contribua para crescimento do regente e do coro; envolver os coralistas no processo de seleção musical.

Os aspectos específicos ao coro juvenil, a partir dos textos levantados, referentes a escolha de repertório são: 
- Critérios técnicos: necessidades relacionadas à muda vocal; tessituras das vozes juvenis; sonoridade da voz juvenil, pois um coro de adolescentes não deve ser trabalhado sonoramente como vozes adultas; prezar por obras escritas especificamente para a formação coral juvenil, empregando a configuração SAB, ao invés de SATB, onde a linha vocal escrita para os meninos que cantam de barítono, abarque a tessitura de Ré2 a Ré3, atentando, ainda, para que a linha vocal de alto, escrita para as meninas, não seja grave, atingindo notas de Si2 para baixo; selecionar obras que se adaptam às vozes dos adolescentes e não ao contrário. A observação desses critérios proporcionará uma valorização da natureza e sonoridade vocal do adolescente; pesquisar obras eruditas e contemporâneas adequadas às vozes juvenis, para evitar uma tendência que há, no Brasil, dos coros juvenis em realizar arranjos de música popular brasileira os quais, muitas vezes, não são arranjados para essa formação vocal, apresentando, por vezes, uma tessitura voltada para uma região grave da voz das meninas, de modo a não privilegiar, por exemplo, a região de brilho - Ré4-Fá4, daquelas que cantam no naipe de soprano; necessidade de pesquisa de repertório para essa formação; pela falta de repertório específico para vozes juvenis, o regente tem uma necessidade maior de criar/compor e adaptar peças para o coro juvenil que está sob sua orientação; variar o acompanhamento instrumental para ampliar possibilidades de timbre e aperfeiçoamento das habilidades de afinação; escolher repertório que preze pela saúde vocal dos adolescentes; selecionar repertório que possibilite ao adolescente aprender música por meio dele, pois em cada obra podemos trabalhar os mais variados aspectos da linguagem musical, de modo que se possa contribuir para a formação artístico-pedagógica do jovem cantor.

- Critérios gerais: o repertório precisa envolver emocionalmente os integrantes do coro juvenil, pois os adolescentes podem apresentar maior resistência, comparativamente aos adultos, para executar obras que não se sentem, de algum modo, atraídos por elas; perfil social do coro e seus componentes; repertório que propicie desenvolvimento crítico e estético desses participantes que estão em formação. 
MIGUEL, Fábio. PEDROZO, Willian Gomes, TINEO, Emerson Pereira, PANELLI, Felipe Pillis, PEREZ, Felipe Rodrigues Ferreira, SANTOS, André dos, JACINTO, Maicon Pereira, AMARAL, Regina Célia Corso Marcondes do. Questões acerca do repertório no contexto coral adulto e juvenil. Revista Vórtex, Curitiba, v.8, n.2, p. 1-27, 2020.

\section{Considerações gerais}

A escolha de repertório não é tarefa fácil, seja para o regente do coro adulto ou juvenil. $\mathrm{O}$ repertório é um núcleo importante da atividade coral, por meio do qual seus participantes vivenciam música e aprendem a respeito dela. De certa forma o repertório irá evidenciar o que o grupo é capaz de construir coletivamente, sob a orientação do regente e apresentar ao público. Desta maneira não é possível pensar em repertório para qualquer que seja o grupo e seus ouvintes, sem o estabelecimento de critérios claros e bem fundamentados.

Os diversos itens, pertinentes a seleção do repertório coral, agrupados em critérios técnicos e critérios gerais, norteiam a escolha das obras adequadas a cada faixa etária. Contudo, os critérios técnicos e gerais não devem ser tratados de modo separado, mas precisam ser vistos em sua conexão para que o repertório possibilite um fazer musical pedagógico e artístico. Com a definição de critérios para escolha de repertório, podemos selecionar músicas que tenham diversos desdobramentos e influências - social, cultural, artística - sobre a vida daqueles que ouvem ou executam tais obras.

Embora os critérios não devam ser tomados de modo isolado, destacamos uma variável geral, sugerida por Almeida, relacionado ao canto coral adulto, e por Brinson e Demorest, referente a atividade coral com adolescentes. Os autores sugerem o envolvimento dos participantes do coro no processo de escolha de repertório. O envolvimento dos participantes na escolha do repertório, pode parecer ao leitor um aspecto óbvio, no entanto, são poucos os textos escritos acerca do assunto, principalmente, como foi apresentado por Brinson e Demorest, os quais trazem uma sugestão detalhada de como realizar esse processo de envolvimento dos integrantes do coro na seleção do repertório, o que evidencia uma possibilidade de trabalho colaborativo com vistas ao aprendizado musical e desenvolvimento da autonomia dos participantes dentro uma atividade predominantemente coletiva.

Identificamos, ainda, que em relação ao coro juvenil alguns parâmetros, na escolha de repertório, são específicos a essa configuração, e dentre os critérios técnicos, consideramos três: as tessituras da voz juvenil, a muda vocal, a sonoridade da voz juvenil, como pontos diferenciadores em relação à seleção de obras para um coro adulto. O conhecimento desses parâmetros ajudará o regente 
MIGUEL, Fábio. PEDROZO, Willian Gomes, TINEO, Emerson Pereira, PANELLI, Felipe Pillis, PEREZ, Felipe Rodrigues Ferreira, SANTOS, André dos, JACINTO, Maicon Pereira, AMARAL, Regina Célia Corso Marcondes do. Questões acerca do repertório no contexto coral adulto e juvenil. Revista Vórtex, Curitiba, v.8, n.2, p. 1-27, 2020.

a não tratar as vozes juvenis como adultas, exigindo delas uma sonoridade inadequada à faixa etária e que poderá trazer prejuízos à saúde vocal dos adolescentes. No entanto, esses critérios técnicos não podem ser impeditivos para que o regente, por exemplo, selecione repertório que envolva emocionalmente os adolescentes e seja entusiasmante para todos.

O regente precisa fazer uma pesquisa contínua de repertório para ampliar o seu conhecimento, evitando assim selecionar repertório que não seja adequado ao seu coro e, também, para que possa ter possibilidades de variar o gênero, o estilo, a forma, com obras de diferentes períodos e variados compositores. Assim, o regente deve estar atento à necessidade de criar/compor/arranjar para o coro sob sua orientação para que se execute peças que se adaptem às vozes dos coralistas e não ao contrário. Cada vez mais, consideramos, relevante, que o regente desenvolva suas habilidades para compor e arranjar para o seu próprio coro. Cada grupo tem suas facilidades e dificuldades musicais e vocais, que só o seu regente conhece, de modo que é preciso pensar nas particularidades de cada coral, no que tange as possibilidades de repertório.

Temos consciência que, seja para o coro adulto ou juvenil, são muitos os critérios a serem observados na escolha do repertório e, em muitas ocasiôes, não será possível dar conta de todos eles; entretanto, consideramos que é importante que o regente os conheça e os aplique, na medida do possível, com os coros que estão sob sua orientação visando, sempre, um aprendizado musical significativo por meio do repertório, conectando as diferentes variáveis que estão ligadas à atividade coral, sejam elas musicais ou extramusicais.

\section{REFERÊNCIAS}

ALMEIDA, Matheus Cruz Paes. Escolbendo o repertório coral: uma tarefa de regentes? Revista Música Hodie, Goiânia, V.16 - n.2, 2016, p. 25-34. Disponível em revistas.ufg.br/musica/article/view/45212/22395. Acesso em 13/06/2019.

ANDRADE, Débora. PER MUSI - Revista Acadêmica de Música - n.31, 353p., jan. - jun., 2015. Disponível em http://www.scielo.br/scielo.php?script=sci_arttext\&pid=S151775992015000100345\&lng=en\&nrm=iso\&tlng=pt. Acesso em 30/11/2019.

BRINSON, Barbara A., DEMOREST, Steven M. Choral Music: Methods and Materials. 2a ed. Boston: Schirmer, 2014. 
MIGUEL, Fábio. PEDROZO, Willian Gomes, TINEO, Emerson Pereira, PANELLI, Felipe Pillis, PEREZ, Felipe Rodrigues Ferreira, SANTOS, André dos, JACINTO, Maicon Pereira, AMARAL, Regina Célia Corso Marcondes do. Questões acerca do repertório no contexto coral adulto e juvenil. Revista Vórtex, Curitiba, v.8, n.2, p. 1-27, 2020.

COSTA, Patrícia. Coro juvenil nas escolas: sonho ou possibilidade? Música na educação básica. Porto Alegre, v. 1, n. 1, outubro de 2009. ISSN 2175 3172. Disponível em bemeducacaomusical.com.br/revista_musica/ed1/pdfs/7_coro_juvenil_nas_escolas.pdf. Acesso em: 06/07/2015.

COSTA, Patrícia. Características do repertório para coro juvenil: verificação de especificidades. Tese (doutorado) - Universidade Federal do Estado do Rio de Janeiro, Programa de Pós-graduação em Música, Rio de Janeiro, 2017.

COSTA, Patrícia. As características de um coro juvenil. In: V Simpósio de Pós-graduandos em Música. Anais. 2018. Disponível em:

http://www.seer.unirio.br/index.php/simpom/article/view/7779. Acesso em: 12/06/2019.

EMMONS, Shirlee; CHASSE, Constance. Prescriptions for choral excellence: tone, text, dynamic leadership. Oxford; New York: Oxford University Press, 2006.

FRANCHINI, Rogéria Tatiane Soares. Canto coral com adolescentes: publicações brasileiras. Anais da ABEM (2015). Disponível em

http://abemeducacaomusical.com.br/conferencias/index.php/xxiicongresso/xxiicongresso/paper/vi ew/1270. Acesso em 16/06/2019.

MAGRE, Fenando; BERG, Silvia Mairia Pires Cabrera. Estratégias para a performance de música contemporânea com coros amadores: Beba Coca Cola de Gilberto Mendes e o Coro Juvenil da UEL. Anais da ANPPOM. Disponível em http://www.anppom.com.br/congressos/index.php/25anppom/Vitoria2015/paper/view/3445. Acesso em 24/10/2019.

FIGUEIREDO, Carlos Alberto. Reflexôes sobre aspectos da Prática Coral. In: Ensaios - Olhares sobre a música coral brasileira. 2010. Disponível em:

http://www.sisbin.ufop.br/novoportal/arquivos/livros/1.pdf. Acesso em: 09/07/2015.

GABRIEL, Vitor. Repertório. Texto produzido para VIII Clínicas Musicais para professores do Guri Santa Marcelina, realizada de 23 a 26 de julho de 2018. n. p.

GABRIEL, Vitor; MIGUEL, Fábio: Apostila das Clinicas Musicais de Regência Coral para professores do Grui Santa Marcelina, realizada em janeiro de 2014. n.p.

GABORIM-MOREIRA, Ana Lúcia Iara. Regência coral infantojuvenil no contexto da extensão universitária: a experiência do PCIU. Tese (doutorado) - Escola de Comunicações e Artes, Programa de Pós-graduação em Música, Universidade de São Paulo, São Paulo, 2015.

MIGUEL Fábio; MOUTINHO, Lucas Gonçalves; ANSELMI, Luís Guilherme; JANSON Silvio Fernando; PEDROZO, Willian Gomes; SANTOS, André Laitano dos; AMARAL, Regina Celia Corso Marcondes do; BULGARELLI, Dayse Rodrigues; FUKUMOTO, Caroline Cabral Romano; RODRIGUES, Thais de Freitas. Oficinas de Canto Coral na Escola Miss Browne: um relato de experiência. Anais da ANPPOM (2017). Disponível em http://www.anppom.com.br/congressos/index.php/27anppom/cps2017/paper/view/4711. Acesso em 15/07/2019 
MIGUEL, Fábio. PEDROZO, Willian Gomes, TINEO, Emerson Pereira, PANELLI, Felipe Pillis, PEREZ, Felipe Rodrigues Ferreira, SANTOS, André dos, JACINTO, Maicon Pereira, AMARAL, Regina Célia Corso Marcondes do. Questões acerca do repertório no contexto coral adulto e juvenil. Revista Vórtex, Curitiba, v.8, n.2, p. 1-27, 2020.

MIGUEL, Fábio; UTSUNOMIYA, Mirian Megumi. O último som da inocência: exercícios vocais, adequação de repertório, muda vocal". Texto produzido para a palestra proferida para os professores do Projeto Guri Santa Marcelina, na capacitação Clinicas Musicais realizada de 21 a 24 de julho de 2015.

OLIVEIRA, Carolina Andrade; IGAYARA-SOUSA, Susana Cecília. O conceito de arranjo coral no repertório brasileira. Anais da ANPPOM (2017). Disponível em http://www.anppom.com.br/congressos/index.php/27anppom/cps2017/paper/view/4771. Acesso $\underline{\text { em } 24 / 10 / 2019}$

PAZIANI, Juliana Damaris de Santana. Coro infantojuvenil nos grupos corais do Projeto Guri Regional Ribeirão Preto: repertório e formação do regente (educador musical). Dissertação (mestrado) - Universidade Estadual Paulista "Júlio de Mesquita Filho”, Programa de Pós-graduação em Música, São Paulo, 2015

SILVA, Luiz Eduardo; FIGUEIREDO, Sérgio Luiz Ferreira. Prática coral: um panorama das publicações de anais de encontros e congressos da ABEM e ANPPOM dos últimos dez anos (20032013). Anais da ABEM (2015). Disponível em http://abemeducacaomusical.com.br/conferencias/index.php/xxiicongresso/xxiicongresso/paper/vi ew/1092. Acesso em 16/06/2019.

SILVA, Luiz Eduardo. O ensino e a aprendizagem da técnica vocal em corais amadores a partir da concepção de regentes e cantores. Dissertação (Mestrado) - Universidade do Estado de Santa Catarina, Centro de Artes, Programa de Pós-Graduação em Música, Florianópolis, 2017.

SCHIMITI, Lucy Maurício. Regendo um Coro Infantil... reflexóes, diretrizes e atividades. Canto coral: Publicação Oficial da Associação Brasileira de Regentes de Coros. Goiás, ano II, n.o 1, 2003. p.15-18.

SOUSA, Ediel Rocha de. A música paraense no repertório do Coro Universitário da UFPA. Anais da ANPPOM (2018). Disponível em http://www.anppom.com.br/congressos/index.php/28anppom/manaus2018/paper/view/5454. Acesso em 24/10/2019.

ZIELINSKI, Richard. The Performance Pyramid: Building Blocks for a Successful Choral Performance. Music Educators Journal, Vol. 92, No. 1 (Sep., 2005), pp. 44-49. https://www.jstor.org/stable/3400226. Acesso em 25/05/2019.

\section{SOBRE OS AUTORES}

Fábio Miguel: Cantor, Professor de Canto e Regente Coral. Bacharel em Regência pela Universidade Estadual Paulista Júlio de Mesquita Filho no Instituto de Artes de São Paulo. Mestre em Música pela mesma universidade. Doutor em Música, também, pela UNESP. Desde 2008 é professor no Instituto de Artes da UNESP. Pesquisa acerca dos significados da voz em diferentes ambientes sonoros, bem como a respeito da Expressão Vocal no Canto Coral. Líder do GEPPEVOZIA (Grupo de Estudo, Prática e Pesquisa em Voz do Instituto de Artes da UNESP). ORCID: https://orcid.org/0000-0002-6324-4067. Email: fabbyomi@hotmail.com 
MIGUEL, Fábio. PEDROZO, Willian Gomes, TINEO, Emerson Pereira, PANELLI, Felipe Pillis, PEREZ, Felipe Rodrigues Ferreira, SANTOS, André dos, JACINTO, Maicon Pereira, AMARAL, Regina Célia Corso Marcondes do. Questões acerca do repertório no contexto coral adulto e juvenil. Revista Vórtex, Curitiba, v.8, n.2, p. 1-27, 2020.

Willian Gomes Pedrozo: Mestre em Música pela Universidade Estadual Paulista "Júlio de Mesquita Filho" (UNESP) e Bacharel em Regência pela mesma universidade. Técnico em Música, Habilitado em Contrabaixo Elétrico pela Fundação das Artes de São Caetano do Sul. Atua como Regente Coral, instrumentista e compositor. Como pesquisador se dedica a investigação de Música Vocal, sobretudo a ligada a Grande Guerra. ORCID: https://orcid.org/0000-0002-3689-0047. Email: williangomesbass@hotmail.com

Emerson Pereira Tineo: Possui bacharelado em Composição e Regência e em Licenciatura em Educação Musical pelo IA/Unesp - Universidade Estadual Paulista Júlio de Mesquita Filho, cursa mestrado em Música pelo mesmo instituto sendo orientado pelo prof. Dr. Fábio Miguel. Regente de corais amadores, professor do CPS - Centro Estadual de Educação Tecnológica Paula Souza, também é coordenador artístico pedagógico da área de canto coral, iniciação e fundamentos da música da Sustenidos Organização Social de Cultura. ORCID: https://orcid.org/0000-0003-2630-753X. Email: eptineo@gmail.com

Felipe Pillis Panelli: Nascido em São Paulo, começou seus estudos em música aos 8 anos de idade no Conservatório Musical Beethoven onde teve aulas de piano e contrabaixo elétrico. Atualmente é graduando no curso de bacharelado em composição musical da Unesp. Terminou, em 2020, uma Iniciação Científica fomentada pela FAPESP e pelo CNPq. Além disso, estuda canto e teve participação como solista em concertos com a Orquestra Acadêmica da Unesp nos anos de 2018 e 2019. É integrante do GEPPEVOZIA (Grupo de Estudo, Prática e Pesquisa em Voz do Instituto de Artes da Unesp). ORCID: https://orcid.org/0000-0003-0701-2840. Email: felipe.panelli@unesp.br

Felipe Rodrigues Ferreira Perez: Natural de Araraquara-SP. Bacharel em Ciências Sociais pela Universidade De São Paulo (USP) e, atualmente, graduando em Composição Eletroacústica pela Universidade Estadual Paulista "Juilio de Mesquita Filho" (UNESP). Atuou como produtor musical na produtora Play It Again no ano de 2017, e atua desde 2012 como cantor e violonista popular; atua também como compositor e instrumentista de música de concerto. Como pesquisador se dedica à Música Vocal, com foco na investigação sobre a relação texto-música na música contemporânea. ORCID: https://orcid.org/0000-0003-4487-1580. Email: $\underline{\text { felipe.perez@unesp.br }}$

André dos Santos: Natural de Santos - SP. Se formou em Licenciatura em Música pela UNISANTOS (2015), atualmente é graduando em Bacharelado em Regência (UNESP). Atou como cantor no Coro Municipal do Guarujá (2013-2014); Regente no projeto Coro e Camerata Caiçara (2014-2015); Regente convidado para a estreia da peça Ave Matter de Diego Sposito UNISANTOS (2014) e Regente e Produtor Musical na Cia Diagonal no Concerto "In Concert: Músicas e Musicais da Broadway com o cantor britânico Martin Callaghan. Atualmente é Regente titular do Coral Nossa Senhora da Saúde e Regente Assistente da Orquestra Filarmônica Sinos Azuis. ORCID: https://orcid.org/0000-0002-8153-619. Email: andrelaitanods@gmail.com

Maicon Pereira Jacinto: Natural de Sorocaba, interior de São Paulo, iniciou seus estudos musicais aos 8 anos, cursou violino no Instituto Municipal de Música de Sorocaba e no Conservatório Dramático Musical Dr. Carlos de Campos de Tatuí. Foi membro integrante de diversos grupos artísticos destas instituiçóes, como a Orquestra de Cordas, Orquestra Jovem e Coral adulto do Instituto de Música de Sorocaba; Orquestra Jovem, Coro de Câmara e Coro jovem do Conservatório de Tatuí. Atualmente cursa Licenciatura em Música no Instituto de Artes da UNESP, sendo bolsista de Iniciação Científica (PIBIC); participa ativamente dos grupos: Camerata Guarany, Coro Osvaldo Lacerda e SabIa Coro. ORCID: https://orcid.org/0000-0002-3689-0047. Email: maicon.pereira@unesp.br 
MIGUEL, Fábio. PEDROZO, Willian Gomes, TINEO, Emerson Pereira, PANELLI, Felipe Pillis, PEREZ, Felipe Rodrigues Ferreira, SANTOS,

André dos, JACINTO, Maicon Pereira, AMARAL, Regina Célia Corso Marcondes do. Questões acerca do repertório no contexto coral adulto e juvenil. Revista Vórtex, Curitiba, v.8, n.2, p. 1-27, 2020.

Regina Célia Corso Marcondes do Amaral: Graduanda em Regência pela Universidade Estadual Paulista (UNESP). Em 2016, passou a integrar o Grupo de Estudo, Prática e Pesquisa em Voz do Instituto de Artes da UNESP (GEPPEVOZIA). De 2016 e 2017, integrou o Coro de Câmara da mesma instituição. De 2017 a 2019 correpetiu no coral do Instituto Federal de São Paulo (IFSP) e integrou o Madrigal Padre José Maurício. Desenvolve trabalho de Iniciação Cientìfica na área de Regência Coral. Atualmente é regente do grupo de percussão "Orquestra de Objetos Desinventados” e produtora da Orquestra Acadêmica da UNESP. Trabalha, também, como tradutora e intérprete alemão, polonês e português. ORCID: https://orcid.org/0000-0003-3203-8903. Email: regina.marcondes.amaral@gmail.com 